\title{
REFLEXÕES E CONTRIBUIÇÕES AOS ESTUDOS DE RISCO E JUSTIÇA AMBIENTAL NA BAIXADA FLUMINENSE, DUQUE DE CAXIAS-RJ
}

\author{
Amauri Alves Meira Lima. \\ Licenciando em Geografia, Faculdade de Educação da Baixada Fluminense/UERJ; \\ amauri_alves@hotmail.com \\ Andréa Paula de Souza. \\ Professor DEGEO, Faculdade de Educação da Baixada Fluminense/UERJ; \\ andrea.souza@uerj.br
}

RESUMO: Um dos grandes problemas encontrados hoje nas metrópoles do Brasil e do mundo estão pautados na problemática de eventos adversos sobre determinados territórios, causando danos humanos, materiais, ambientais, econômicos, políticos e sociais. Dentre os fenômenos que mais se destacam, citamos as inundações, enchentes e corridas de detritos. Esses processos naturais, muitas vezes agravados pela ação antrópica de uso e ocupação do solo urbano, acabam sendo de interesse a muitos pesquisadores, pois afetam principalmente espaços onde estão localizadas cidades, grupos sociais, redes de infraestrutura e redes de fluxos. Desta forma, tem-se como objetivo debater questões socioambientais pautadas nos conceitos de risco, vulnerabilidade e justiça ambiental para a Baixada Fluminense (historicamente conhecida como uma zona de sacrifício dentro da metrópole do Rio de Janeiro), onde se compreende que todos devem ter o direito a um tratamento justo, independente de renda ou origem dos grupos sociais, e a um meio ambiente saudável. Importante ressaltar a questão do risco socioambiental, onde se entende que ao se perceber que os moradores da Baixada Fluminense estão em um espaço desprivilegiado, a partir do território, os quais foram induzidos a utilizar e ocupar áreas mais suscetíveis a enchentes e inundações, onde compreendemos que os riscos socioambientais sentidos por essa população são indicadores de um desenvolvimento desigual.

PALAVRAS CHAVE: Risco, Vulnerabilidade, Justiça Ambiental e Baixada Fluminense 


\section{REFLECTIONS AND CONTRIBUTIONS TO RISK STUDIES AND ENVIRONMENTAL JUSTICE IN THE BAIXADA FLUMINENSE, DUQUE DE CAXIAS-RJ}

ABSTRACT: One of the major issues faced nowadays in the cities of Brazil and the world are based on the problem of adverse events on certain areas, causing human, material, environmental, economic, political and social damage. Among the phenomenons that stand out, we quote the floods, flooding and debris flow. These natural processes, often aggravated by human activities use and occupation of urban land, become the interest for many researchers because these events affect mainly areas where cities, social groups, infrastructure networks and flows of networks are located. Therefore, it has aimed to discuss environmental issues based on the concepts of risk, vulnerability and environmental justice for the Baixada Fluminense (historically known as a sacrificial zone within the metropolis of Rio de Janeiro), where it is understood that everyone should have right to fair treatment, regardless of income or source of social groups, and a healthy environment. It is important to emphasize the issue of environmental risk, for the understanding when it is realized that the inhabitants of the Baixada Fluminense are in a disadvantaged area, for the territory, which they have been induced to use and occupy areas more susceptible to flooding, we comprehend that the environmental risks experienced by this population indicate irregular development.

Key Words: Risk, Vulnerability, Environmental Justice and Baixada Fluminense 


\section{INTRODUÇÃO}

As populações dos centros urbanos são cada vez mais alvos de problemas ambientais, pois as cidades crescem, modificam e se expandem para as periferias, perpassando os fundos de vales e se concretizam na verticalização das regiões centrais. A expansão desses centros produzida pela demanda de áreas e pelas restrições políticas, que induzem o uso da terra implica na vulnerabilidade da população. Pode-se dizer que uma grande parcela da população, principalmente nos países sul-americanos, vive em moradias precárias, em locais de pouca infraestrutura e serviços deficientes. E aliado a tal têm-se as inundações como um dos principais desastres, ocupando a nível mundial a quarta posição em vítimas fatais e terceira em prejuízos econômicos nas últimas décadas (NUNES, 2015).

As inundações se configuram como um dos principais fatores de riscos naturais das diversas regiões e cidades brasileiras. Entretanto passa a condição de enchente quando um fenômeno natural passa a ser agravado pelas áreas urbanas. A ocupação irregular ao longo do sistema de drenagem faz com que as enchentes configuram-se como um dos fenômenos mais impactantes e prejudiciais ao ser humano. Por isso, os processos naturais relacionados aos altos índices pluviométricos como inundações, enchentes e deslizamentos, ao entrar em contato com os grupos sociais de um determinado território decorrem na formação de riscos e de vulnerabilidades.

Nesta perspectiva e não diferente ao contexto exposto acima se tem a Baixada Fluminense, importante região Estado do Rio de Janeiro. Importância que permeia desde seu contingente populacional, a economia, assim como os sistemas naturais que são de grande relevância. Desta forma, pretende-se colaborar com a discussão dos conceitos de risco, vulnerabilidade e território e suas inter-relações para assim melhor compreender a real dimensão dos problemas do uso e ocupação do solo da Baixada Fluminense e de como os moradores da região são afetados pela ausência de políticas públicas habitacionais e ambientais, onde a grande parcela da população espacialmente 
segregada e ausente de poder político na construção e participação do espaço urbano sofre com as consequências desse modelo de desenvolvimento concentrador e excludente (ROLNIK, 2008).

\section{RISCO, VULNERABILIDADE E TERRITÓRIO}

É importante ressaltar que a noção de risco é complexa e que a geografia tem como fundamento o interesse pelas relações sociais, ambientais e por suas traduções espaciais. São muitos os fatores geradores de perigos percebidos e sentidos pela sociedade como riscos. Com isso manifesta-se que a gestão do risco traduz escolhas políticas na organização dos territórios, o que ressalta a importância da geografia para a análise crítica do risco, pois o espaço geográfico não é neutro, ele é socialmente construído por meio de diversas intencionalidades, através de diversos agentes produtores (dominantes) do espaço, principalmente via posse e controle do uso da terra (CORRÊA, 1995), fazendo com que determinados grupos sociais estejam desprotegidos e expostos a diversas problemáticas sociais, ambientais, sanitárias e políticas.

Diante desse contexto e através da base teórica de Yvette Veyret, o risco definese como: "Percepção de um perigo possível, mais ou menos previsível por um grupo social ou por um indivíduo que tenha sido exposto a ele." (VEYRET, 2013, p.24). Percebe-se então que o risco e sua percepção não podem ser evidenciados sem que se considere o processo que o produziu e, principalmente, as relações com o espaço geográfico, os modos de ocupação do território, de suas diversas relações sociais e de suas escolhas ou omissões políticas.

Para melhor compreensão do tema, deve-se saber que há diversas categorias de risco, porém, ao longo desse trabalho se abordará as categorias de risco natural e risco socioambiental. A percepção espacial dos riscos é de grande interesse para a geografia para um melhor entendimento sobre a temática, uma vez que se nota ao longo desse trabalho que os riscos, ou seja, a percepção de um possível perigo para a própria população ou para seus bens estão espacialmente distribuídos de maneira desigual e injusta perante a relativa fraqueza política e econômica dos grupos sociais (ACSELRAD, et.al, 2009). 
A definição de risco só pode ser compreendida a partir do momento em que se observa que não há riscos sem as populações (grupos sociais) ou indivíduos que o perceba e que pode sofrer suas consequências, ou seja, o conceito de risco é a representação de um perigo para aquele que está sujeito a ele e o percebe como uma ameaça possível a sua vida ou a seus bens (VEYRET, 2013). Segundo o Ministério da Integração Nacional - Secretaria Nacional de Defesa Civil, o Glossário de Defesa Civil Estudos de Riscos e Medicina de Desastres, define risco como:

“ 1. Medida de dano potencial ou prejuízo econômico expressa em termos de probabilidade estatística de ocorrência e de intensidade ou grandeza das conseqüências previsíveis. 2. Probabilidade de ocorrência de um acidente ou evento adverso, relacionado com a intensidade dos danos ou perdas, resultantes dos mesmos. 3. Probabilidade de danos potenciais dentro de um período especificado de tempo e/ou de ciclos operacionais. 4. Fatores estabelecidos, mediante estudos sistematizados, que envolvem uma probabilidade significativa de ocorrência de um acidente ou desastre. 5. Relação existente entre a probabilidade de que uma ameaça de evento adverso ou acidente determinado se concretize e o grau de vulnerabilidade do sistema receptor a seus efeitos" (CASTRO, sem data, p.162).

Considera-se assim que, além disso, o conceito de risco expressa a dimensão social e ambiental de possíveis eventos catastróficos que podem vir a acontecer, como a percepção individual ou de determinados grupos sociais de seus efeitos, o que pode auxiliar a tomada de decisões para a gestão do território. Portanto o conceito de risco indica a probabilidade de algum dano, lesando pessoas e/ou bens materiais, e que a necessidade de estudos para políticas de prevenção e planejamento se processe de modo igualitário sem discriminar nenhum indivíduo ou determinado grupo social, para que não possa haver o que pode ser entendido como uma proteção "ambiental desigual” (ACSELRAD, et.al, 2009).

Apesar dos inúmeros tipos de riscos existentes, aprofunda-se aqui a categoria de risco natural, ou seja, enfatiza-se o processo físico de um acontecimento possível. Podendo ser de origem litosférica e/ou hidroclimática, como no caso aqui apresentado as inundações provenientes de deslizamentos. A geografia tem um papel importante ao se preocupar com os fenômenos naturais que, em muitas situações, causam danos materiais e atingem as populações ao perigo, 
DOI: 10.12957/hne.2014.20271

tornando possível assim à ideia de risco natural. Os riscos naturais têm causas físicas que escapam à intervenção humana (RICHEMOND e VEYRET, 2013). Denomina-se risco natural: "Designamos riscos naturais aqueles que são pressentidos, percebidos suportados por um grupo social ou indivíduo sujeito à ação possível de um processo físico, de uma álea" (RICHEMOND e VEYRET, 2013, p.64).

O risco muitas vezes é percebido através de efeitos negativos sobre o indivíduo ou grupo social, e esses efeitos se traduzem seja na perda de bens, seja na morte, seja na doença via ausência de condições sanitárias mínimas. Em muitos casos, nas cidades brasileiras e de muitos outros países periféricos, a expansão urbana não controlada e os deficientes serviços de abastecimento de água, energia e tratamentos sanitários são fatores de risco (RICHEMOND e VEYRET, 2013).

Importante ressaltar que há inúmeros tipos de riscos e que os diferentes fatores de risco evocados interagem uns com os outros, de modo que alguns riscos pertencem simultaneamente a diversas categorias, mostrando assim a complexidade do tema abordado. Assim, podemos enumerar os riscos como: riscos naturais, riscos ambientais, riscos industriais, riscos tecnológicos, riscos econômicos, riscos geopolíticos, riscos sociais, riscos sanitários, e uma infinidade de riscos existentes. Entretanto ao longo desse trabalho, foca-se no risco socioambiental.

Como risco socioambiental entende-se que ao se perceber que os moradores das periferias brasileiras estão em um espaço desprivilegiado, através de uma questão territorial, a qual foram induzidos a utilizar e ocupar áreas mais suscetíveis a enchentes e inundações. Ou seja, nota-se que o conceito de risco socioambiental remete geralmente a ideia de segregação, fragmentação urbana e aos processos físicos suportados por um grupo social pela ocupação de um território vulnerável historicamente construído.

Importante ressaltar que os riscos sanitários estão inseridos dentro da categoria de risco socioambiental. Uma vez que se observa que um ambiente degradado aliado a uma expansão urbana não planejada (formando espaços desiguais), a 
DOI: 10.12957/hne.2014.20271

qual há grande deficiência nas questões relacionadas ao saneamento básico, deficiência do tratamento de esgoto e proliferação de doenças geram agravos e injustiças a determinados grupos sociais territorialmente segregados. $\mathrm{Na}$ realidade da Baixada Fluminense e de muitas outras periferias brasileiras, todos esses fatores são muito comuns e até mesmo "naturalizados".

Ao relacionar a realidade da população periférica/segregada com os riscos sentidos por essa mesma população, compreende-se que os riscos socioambientais são indicadores de um desenvolvimento desigual (RICHEMOND e VEYRET, 2013) assim, como também afirma Neil Smith ao falar da produção de espaços desiguais onde afirma:

"O desenvolvimento desigual é tanto o produto quanto a
premissa geográfica do desenvolvimento capitalista. Como
produto, o padrão é altamente visível na paisagem do
capitalismo, tal como a diferença entre espaços desenvolvidos e
subdesenvolvidos em diferentes escalas: o mundo desenvolvido
e o subdesenvolvido, as regiões desenvolvidas e as regiões em
declínio, os subúrbios e o centro da cidade. Como premissa da
expansão capitalista, o desenvolvimento desigual pode ser
compreendido somente por meio de análise teórica da produção
capitalista da natureza do espaço. O desenvolvimento desigual
é a desigualdade social estampada na paisagem geográfica e é
simultaneamente a exploração daquela desigualdade geográfica
para certos fins sociais determinados" (SMITH, 1988, p.221).

Portanto, através da leitura da produção do espaço de Smith, afirma-se que o espaço geográfico não é neutro, ele é socialmente construído por meio de diversas intencionalidades, onde o urbanismo desregrado e a segregação espacial criam exposições desiguais aos riscos (THOURET, 2013), onde se percebe que a capacidade de recuperação das áreas periféricas/segregadas são muito deficientes e conflituosas, havendo assim uma proteção "ambiental desigual" (ACSELRAD, et.al, 2009) devido a relativa fraqueza política e econômica dos grupos sociais presentes nos espaços desprivilegiados/periféricos.

Ao se falar da fraqueza política e econômica dos grupos sociais, elucida-se que, uma parcela da população está exposta a sofrer fortes riscos socioambientais, ou seja, uma parcela da população vive em uma condição de vulnerabilidade, onde fatores sociais, econômicos, ambientais, políticos e sanitários 
frequentemente aumentam a vulnerabilidade das populações ameaçadas (RICHEMOND e VEYRET, 2013). Por meio desse pensamento considera-se então que a vulnerabilidade é socialmente produzida, onde as exposições aos riscos se impõem aos mais desprotegidos, ou seja, aos vulneráveis, ou melhor, dizendo, aos vulnerabilizados.

Deve-se entender que ao se falar de vulnerabilidade devemos levar em consideração o conceito de risco. Estar vulnerável está relacionado à exposição, à resistência e superação (ou não) de perigos/desastres possíveis. Com isso o Ministério da Integração Nacional - Secretaria Nacional de Defesa Civil, o Glossário de Defesa Civil Estudos de Riscos e Medicina de Desastres, define vulnerabilidade como:

“1. Condição intrínseca ao corpo ou sistema receptor que, em interação com a magnitude do evento ou acidente, caracteriza os efeitos adversos, medidos em termos de intensidade dos danos prováveis. 2. Relação existente entre a magnitude da ameaça, caso ela se concretize, e a intensidade do dano conseqüente. 3. Probabilidade de uma determinada comunidade ou área geográfica ser afetada por uma ameaça ou risco potencial de desastre, estabelecida a partir de estudos técnicos. 4. Corresponde ao nível de insegurança intrínseca de um cenário de desastre a um evento adverso determinado. Vulnerabilidade é o inverso da segurança" (CASTRO, sem data, p.188).

Nas periferias brasileiras (inclusive na Baixada Fluminense), se percebe que grande parte da população encontra-se em situação de vulnerabilidade uma vez que se nota em sua paisagem uma localização habitacional diferenciada no espaço urbano (famílias habitando áreas de risco), emergindo assim a segregação e a produção de espaços desiguais dentro da própria periferia da região metropolitana do Rio de Janeiro (CORRÊA, 1995). Tornando determinados grupos sociais expostos aos riscos de inundações, enchentes, acidentes industriais, deslizamentos, entre outros.

Por apresentar uma fragilidade socioambiental, pode-se dizer que os grupos sociais vulnerabilizados que habitam espaços degradados e segregados, encontram-se em uma situação de injustiça, uma vez que se percebe que para esses grupos restam às terras que a legislação urbanística e ambiental vetou ou indisponibilizou para o assentamento (ROLNIK, 2008), afirmando assim a 
vulnerabilidade dos grupos que habitam áreas propensas a inundações, deslizamentos, enchentes e áreas desprovidas de infraestrutura. Demonstrando que "fatores socioeconômicos frequentemente aumentam a vulnerabilidade das populações ameaçadas" (RICHEMOND e VEYRET, 2013, p.40).

\begin{abstract}
"Para as maiorias, sobram as terras que a legislação urbanística ou ambiental vetou para a construção ou não disponibilizou para o mercado formal, ou os espaços precários das periferias e as viagens cotidianas "à cidade". Embora não exista uma apreciação segura do número total de famílias e domicílios instalados em favelas, loteamentos irregulares, loteamentos clandestinos e outras formas de assentamentos marcados por alguma forma de precariedade urbanística e irregularidade administrativa e patrimonial, é possível afirmar que o fenômeno está presente na maior parte da rede urbana brasileira. No vasto e diverso universo dos 5.564 municípios que existem hoje no Brasil, são raras as cidades que não têm uma parte significativa de sua população assentada precariamente" (ROLNIK, 2008, p.1)
\end{abstract}

Ao dialogar as ideias de ROLNIK, ACSELRAD e VEYRET pode-se dizer que se definem os vulneráveis, ou melhor, dizendo - os vulnerabilizados, como vítimas de uma proteção desigual, onde os riscos sentidos pelos mais desprotegidos estão distribuídos de maneira heterogênea no território. A vulnerabilidade se revela como a fragilidade de determinados grupos sociais em determinada parcela de um território onde o risco encontra-se espacializado.

Para indicar esse fenômeno de imposição desproporcional dos riscos socioambientais para as populações vulnerabilizadas, tem sido consagrado 0 termo injustiça ambiental, ou seja, grupos sociais marginalizados e de menor renda que estão mais sujeitos aos riscos (ACSELRAD, et.al, 2009). Portanto, observa-se que uma população a qual ocupa as margens de um canal fluvial, somado a um ambiente degradada (ausência de condições sanitárias mínimas), possui sua vulnerabilidade ligada aos fenômenos de inundação e ocupação irregular, ou melhor dizendo, sua vulnerabilidade está atrelada aos riscos socioambientais, demonstrando assim as injustiças ambientais sentidas por esses grupos sociais marginalizados. A leitura de espaço de ROLNIK sobre a produção de espaços desiguais (SMITH, 1988) e injustiças aos grupos sociais vulneráveis, demonstra que: 
DOI: 10.12957/hne.2014.20271

"Em uma cidade dividida entre a porção rica, legal e infraestruturada e a porção pobre, ilegal e precária, a população em situação desfavorável acaba tendo muito pouco acesso às oportunidades econômicas e culturais que o ambiente urbano oferece. $\mathrm{O}$ acesso aos territórios que concentram as melhores condições de urbanidade é exclusivo para quem já é parte deles." (ROLNIK, 2008, p.2)

Por conseguinte, observa-se a existência de uma "territorialização" dos riscos, onde a vulnerabilidade está associada à resistência e receptividade do ambiente e da população. Em outras palavras, a vulnerabilidade esta ligada a um fraco preparo para enfrentar a crise e a urgência - deficiência dos poderes públicos (THOURET e VEYRET, 2013) e conflitos com a população diretamente afetada, remetendo-nos mais uma vez a ideia de exposição desigual aos riscos e injustiça ambiental (ACSELRAD, et.al, 2009). Nesse sentido, os riscos socioambientais apresentam-se espacialmente distribuídos.

Ao habitar áreas de risco, elucida-se que o espaço onde os grupos sociais se organizam e ocupam encontram-se expostos aos perigos e desastres possíveis, construindo assim a territorialidade dos riscos e sua condição de vulnerabilidade. É no interior desse espaço que faz surgir os conflitos socioambientais, onde os problemas ambientais estão relacionados a questões e demandas de cunho social. Examina-se que os riscos socioambientais sentidos por essa população são indicadores de um desenvolvimento desigual e que o processo de construção social da vulnerabilidade, causa a necessidade da luta por justiça ambiental nos territórios marginalizados, segregados e em situação de risco.

Para uma melhor compreensão desse fenômeno de imposição desproporcional dos riscos socioambientais para as populações vulnerabilizadas, leva-se em conta a ligação entre os problemas ambientais e as diversas formas de injustiças espacialmente apropriadas (territorializadas), sobre tudo em espaços segregados e fragilizados politicamente, como afirma ACSELRAD:

"A desigualdade ambiental é sem dúvida uma das expressões da desigualdade social que marcou a história do nosso país. Os pobres estão mais expostos aos riscos decorrentes da localização de suas residências, da vulnerabilidade destas moradias a enchentes, desmoronamentos e à ação de esgotos a céu aberto. Há consequentemente forte correlação entre indicadores de pobreza e a ocorrência de doenças associadas à poluição por ausência de água e esgotamento sanitário ou por 
DOI: 10.12957/hne.2014.20271

lançamento de rejeitos sólidos, emissões líquidas e gasosas de origem industrial. Esta desigualdade resulta, em grande parte, da vigência de mecanismos de privatização do uso dos recursos ambientais coletivos - água, ar e solos." (ACSELRAD, 2000, p.1)

Os riscos frequentemente podem ser analisados a partir do território afetado, construindo assim o pensamento de que o risco afeta, em diferentes graus, as cidades e os grupos sociais que ocupam esses espaços. Onde a vulnerabilidade frequentemente varia em função das desigualdades habitacionais dentro de um território, no qual diversos tipos de riscos e injustiças são naturalizados por meio das relações sociais e de poder. Para melhor elucidação dessas relações, se faz importante trazer a ideia de território, onde:

"Como já demonstramos [...] o território não é algo anterior ou exterior à sociedade. Território é espaço apropriado, espaço feito coisa própria, enfim, o território é instituído por sujeitos e grupos sociais que se afirmam por meio dele. Assim, há, sempre, território e territorialidade, ou seja, processos sociais de territorialização. Num mesmo território há, sempre, múltiplas territorialidades. Todavia, o território tende a naturalizar as relações sociais e de poder, pois se torna abrigo, lugar onde cada qual se sente em casa, mesmo que numa sociedade dividida." (PORTO-GONÇALVES, 2006, p.42).

As relações sociais e de poder, criam resistências e sobrevivências que se manifestam na apropriação de terrenos usualmente inadequados (CORRÊA, 1995), como áreas suscetíveis a inundações. Essa resistência corresponde ao problema da habitação e das diferenças de acesso aos bens e serviços produzidos socialmente, isto é, o direito à cidade (LEFEBVRE, 2001). Todavia a segregação de determinados grupos sociais a circuitos de vulnerabilidade, faz coincidir a divisão espacial da degradação ambiental por meio de um forte cunho social.

Portanto o acesso desigual a um meio ambiente justo, saudável e seguro é um grande indicador que se assemelha muito aos "mecanismos de produção da desigualdade social" (ACSELRAD, et.al, 2009, p.76). Onde se percebe que o espaço geográfico é formado por um processo de distribuição desigual da apropriação do meio ambiente em que a vulnerabilidade, a segregação e a pobreza têm seus efeitos visíveis no território. Moradores próximos a cursos d'água são mais vulneráveis aos perigos possíveis de inundações, uma vez que 
se soma a característica de habitar uma área suscetível ao risco natural à sua condição socioeconômica, onde os riscos socioambientais são indicadores de um desenvolvimento desigual em que os grupos sociais são induzidos a ocupar e utilizar espaços degradados e inseguros.

Ao olhar de maneira crítica o acesso desigual a um meio ambiente justo e saudável, averígua-se que os grupos sociais marginalizados/segregados e de menor renda estão mais sujeitos aos riscos consequentes da localização de suas moradias (habitações sobre áreas de risco). Onde a desigualdade social dialoga com a produção de espaços desiguais, originando um território vulnerabilizado, uma vez que ao ocupar terras marginalizadas/segregadas determinados grupos sociais habitam em espaços ambientalmente frágeis e suscetíveis a possíveis situações de perigo, áreas que a principio não deveriam ser urbanizadas.

"Esses processos geram efeitos nefastos para as cidades,
alimentando a cadeia do que eu chamo de um urbanismo de
risco, que atinge as cidades como um todo. Ao concentrar todas
as oportunidades em um fragmento da cidade, e estender a
ocupação a periferias precárias e cada vez mais distantes, esse
urbanismo de risco vai acabar gerando a necessidade de levar
multidões para esse lugar para trabalhar, e devolvê-las a seus
bairros no fim do dia, gerando assim uma necessidade de
circulação imensa, o que nas grandes cidades tem gerado o
caos nos sistemas de circulação. E quando a ocupação das
áreas frágeis ou estratégicas do ponto de vista ambiental
provoca as enchentes ou a erosão, é evidente que quem vai
sofrer mais é o habitante desses locais, mas as enchentes, a
contaminação dos mananciais, os processos erosivos mais
dramáticos, atingem a cidade como um todo." (ROLNIK, 2002,
p.3) A geografia tem como fundamento o interesse pelas relações sociais, ambientais e por suas traduções espaciais sobre os diferentes territórios e territorialidades, para assim, compreender melhor a ampla problemática dos riscos. E que a gestão do risco traduz escolhas ou omissões políticas na organização dos territórios, o que ressalta a importância da geografia para a análise crítica do risco, pois o espaço geográfico não é neutro, ele é produto das diversas intencionalidades dos agentes hegemônicos de produção dos espaços, as ações desses agentes ocorrem dentro de um marco jurídico que legitima suas atuações (CORREA, 1995) e das conflituosas relações sociais no território, ou como diz SANTOS: 
DOI: 10.12957/hne.2014.20271

"A escala do evento é a escala da ação em que o tempo, em seus diferentes ritmos e processos, se efetiva nas conflituosas relações sociais no território, porque na verdade, eventos mudam as coisas, transformam os objetos, dando-lhes, ali mesmo onde estão, novas características." (SANTOS, 2002, p.146)

Analisa-se que o risco e sua percepção não podem ser evidenciados sem que se considerem os processos e atores que os produziu e, principalmente, as relações com o espaço geográfico, os modos de ocupação do território, de suas diversas relações, conflitos e fluxos existentes. Onde a percepção espacial dos riscos é de grande interesse para a geografia para um melhor entendimento sobre a temática, ao fato de que se nota que os riscos, ou seja, a percepção de um possível perigo para a própria população ou para seus bens estão espacialmente distribuídos de maneira desigual e injusta em um determinado território. A geografia toma o risco e a vulnerabilidade em uma ampla dimensão ambiental, social e política, procurando avançar e aprofundar o enriquecimento do debate e lutas por justiça ambiental.

\section{(IN)JUSTIÇA AMBIENTAL E BAIXADA FLUMINENSE:}

A Baixada Fluminense, como parte constituinte da região metropolitana do Rio de Janeiro, compõem-se de treze municípios: Duque de Caxias, São João de Meriti, Nova Iguaçu, Belford Roxo, Nilópolis, Mesquita, Queimados, Magé, Guapimirim, Japeri, Paracambi, Seropédica e Itaguaí.

O histórico de ocupação efetiva da Baixada Fluminense, data que no início do século XX, a ocupação dessas terras por parte da população se deu ao longo das linhas férreas e que a partir do final da década de 1920, uma serie de obras de infraestruturas foram implementadas para tentar solucionar problemas como transportes, saneamento básico e redes de energia. O fim do período da citricultura (laranjais) repercutiu em definitivo a transformação do espaço rural da Baixada Fluminense para um espaço urbano, intensificando a ocupação nas áreas próximas à cidade do Rio de Janeiro, tornando-se alvo de loteamentos urbanos (décadas de 1940 e 1950). 
O grande fluxo de migrantes acarretou na intensificação da ocupação dessa área periférica em relação à influência da cidade do Rio de Janeiro, uma vez que o contingente populacional associado ao alto custo de vida e habitação no Rio de Janeiro buscou loteamentos com baixos custos de moradia dentro da própria Baixada Fluminense. Com isso, percebe-se que a população de baixa renda dirigia-se para áreas cada vez mais distantes e precarizadas, onde os mais pobres estão expostos aos riscos decorrentes da localização de suas residências, habitando espaços ambientalmente frágeis e suscetíveis a possíveis situações de perigo, áreas que a principio não deveriam ser urbanizadas.

\begin{abstract}
"O período 1906-1930 caracterizou-se, ademais pela extensão efetiva do tecido urbano para além das fronteiras do Distrito Federal, dando início, assim, ao processo de integração física da Baixada Fluminense ao espaço carioca. Para tanto, muito contribuíram os trabalhos de saneamento da parte noroeste da baixada mandados executar por Nilo Peçanha, quando presidente do Estado do Rio e da República. Com efeito, embora as estradas de ferro já mantivessem estações nos atuais municípios de São João de Meriti, Nilópolis e Duque de Caxias desde o final do século passado, a ocupação urbana dos mesmos só se concretizou nas primeiras décadas do século XX, quando a baixada foi parcialmente saneada." (ABREU, 1997, p.81)
\end{abstract}

Atualmente, o espaço da Baixada Fluminense possui uma alta concentração de atividades industriais, com presença de grandes parques e distritos industriais em toda a região fluminense. Com isso a Baixada Fluminense se tornou reconhecida por ser uma "zona de sacrifício", ou seja, uma região onde os riscos industriais, sociais, ambientais e políticos são indicadores de uma superposição a empreendimentos, instalações e produções responsáveis por possíveis danos a determinados grupos sociais. Por isso, ABREU nos lembra de que desde o início do século $X X$ até os dias atuais o território da Baixada Fluminense se caracteriza pela ausência de benefícios urbanísticos quando o autor diz que:

"Resumindo, o período de $1906-1930$ caracterizou-se pela
expansão notável do tecido urbano do Rio de Janeiro, processo
esse que se efetuou de maneira distinta no que se refere aos
dois grandes vetores de crescimento da cidade. De um lado, a
ocupação das zonas sul e norte pelas classes média e alta
intensificou-se, e foi comandada, em grande parte, pelo Estado
e pelas campanhias concessionárias de serviços públicos. De 
outro, os subúrbios cariocas e fluminenses cada vez mais se solidificaram com o local da residência do proletariado, que para aí se dirigiu em números crescentes. Ao contrário da área nobre, entretanto, a ocupação suburbana se realizou praticamente sem qualquer apoio do Estado ou das concessionárias de serviços públicos, resultando daí uma paisagem caracterizada principalmente pela ausência de benefícios urbanísticos". (ABREU, 1997, p.82)

A lógica agroexportadora a qual estruturou as cidades brasileiras, e a região da Baixada Fluminense, agora ganha outra dimensão, a lógica de um espaço urbano industrial (processo que ganha força nas décadas de 1930 a 1950). Consolida-se durante esse tempo a condição de espaço periférico da Baixada Fluminense, demonstrando em sua paisagem uma serie de desigualdades e injustiças sanitárias, sociais, ambientais e habitacionais. Ao mesmo tempo, investimentos públicos eram feitos para atrair cada vez mais indústrias para a região e tornar mais ameno os bairros dos grupos sociais dominantes das cidades metropolitanas.

“Já na década de 1920 estavam, pois, lançadas as bases para a
formação da Área Metropolitana do Rio de Janeiro. Sua estrutura
urbana também já se cristalizava, assumindo cada vez mais uma
forma dicotômica: um núcleo bem servido de infra-estrutura,
onde a ação pública se fazia presente com grande intensidade e
onde residiam as classes mais favorecidas, e uma periferia
carente dessa mesma infra-estrutura, que servia de local de
moradia às populações mais pobres, e onde a ação do Estado
era praticamente nula. Esta carência caracterizava, inclusive, o
próprio transporte ferroviário, essencial para a própria
reprodução da força de trabalho" (ABREU, 1997, p.82) Configura-se então que o espaço periférico da Baixada Fluminense é o lugar onde se instala a pobreza e os riscos socioambientais, portanto a Baixada Fluminense torna-se uma zona de sacrifício dentro da metrópole do Rio de Janeiro, demonstrando que a injustiça ambiental incide sobre esse território. Grande parte da população presente em espaços periféricos/segregados não possuem condições mínimas de urbanidade, gerando o chamado urbanismo de risco (ROLNIK, 1997, 2002), ou seja, a população fluminense não tem acesso a uma habitação adequada, transportes coletivos eficientes e serviços públicos básicos de qualidade como saúde, educação e saneamento básico.

"Urbanismo de risco é aquele marcado pela inseguridade, quer do terreno, quer da construção ou ainda da condição jurídica da 
posse daquele território. As terras onde se desenvolvem estes mercados de moradia para os pobres são, normalmente, justamente aquelas que pelas características ambientais são as mais frágeis, perigosas e difíceis de ocupar com urbanização: encostas íngremes, beiras de córregos, áreas alagadiças. As construções raramente são estáveis, e a posse quase nunca totalmente inscrita nos registros de imóveis e cadastros das prefeituras. O risco é, antes de mais nada, do morador: o barraco pode deslizar ou inundar com chuva, a drenagem e o esgoto podem se misturar nas baixadas - a saúde e a vida são assim ameaçadas. No cotidiano, são as horas perdidas no transporte, a incerteza quanto ao destino daquele lugar, o desconforto da casa e da rua."(ROLNIK e CYMBALISTA, 1997, p.7)

Os municípios da região da Baixada Fluminense, e sua fragmentação urbana interna, são grandes exemplos desta realidade urbana os quais se compreendem em um quadro social no qual perpetua as injustiças sobre os grupos sociais mais vulneráveis, onde a classe dominante segrega parcela da população na medida em que controla e domina o mercado de terras (mercado imobiliário e construção civil), conduzindo seletivamente a localização dos grupos sociais no espaço urbano, ao atuar indiretamente ou diretamente através do Estado (CORRÊA, 1995).

A cidade de Duque de Caxias apresenta-se como a cidade mais populosa da Baixada Fluminense e também a cidade que possui o maior e mais importante parque industrial da região metropolitana do Rio de Janeiro. Percebe-se na realidade caxiense que a oferta de bens e serviços está concentrada em determinados pontos do território, formando concentrações econômicas e demográficas, que geram e intensificam as desigualdades internas da cidade.

"Localizado estrategicamente junto às principais rodovias do país, Presidente Dutra, Washington Luís, Avenida Brasil, Linhas Vermelha e Amarela, o município de Duque de Caxias ocupa o segundo lugar no ranking de arrecadação de ICMS do estado do Rio de Janeiro, perdendo somente para a capital, de acordo com pesquisas da Fundação CIDE. Segundo dados do IBGE, Duque de Caxias possui uma população de 872.762 habitantes e um Produto Interno Bruto na ordem de $R \$ 25.001 .454,00$, sendo o PIB per capita de $R \$ 33.398,00[\ldots]$ A arrancada no desenvolvimento econômico do município teve início com a implantação da Refinaria de Duque de Caxias na década de 60. A empresa atraiu também outros gigantes do setor de petróleo: Shell, Texaco, Mobil, Petroflex. Os principais segmentos industriais no município são químico/petroquímico, metalúrgico/gás, plástico, mobiliário, têxtil/vestuário. 
DOI: 10.12957/hne.2014.20271

Atualmente, empresas de vários segmentos têm se instalado em Duque de Caxias, tais como Jornal O Globo, Carrefour, Casas Bahia, aproveitando a privilegiada posição do município, sendo o número de 11.763 unidades de empresas cadastradas, segundo dados do IBGE." (CAMARA MUNICIPAL DE DUQUE DE CAXIAS, 2015)

Duque de Caxias apresenta-se dividida em quatro distritos: 1 - Duque de Caxias, 2 - Campos Elísios, 3 - Imbariê e 4 - Xerém. Ao analisar a realidade do município de Duque de Caxias, percebe-se que a força econômica não está associada à qualidade de vida populacional, uma vez que grande parte dessa população sofre com graves problemas ligados a questões de habitação, ausência de saneamento básico, péssima qualidade nos serviços de saúde e educação e a uma rede de transportes ineficiente e cara.

"1 DISTRITO: Jardim 25 de Agosto, Parque Duque, Periquitos, Vila São Luiz, Gramacho, Sarapuy, Centenário, Centro, Dr. Laureano, Olavo Bilac, Bar dos Cavaleiros, Jardim Gramacho. 2o DISTRITO: Jardim Primavera, Saracuruna, Vila São José, Parque Fluminense, Campos Elíseos, Cangulo, Cidade dos Meninos, Figueira, Chácaras Rio-Petrópolis, Chácara Arcampo, Eldorado. 3ํㅡㄴ DISTRITO: Santa Lúcia, Santa Cruz da Serra, Imbariê, Parada Angélica, Jardim Anhangá, Santa Cruz, Parada Morabi, Taquara, Parque Paulista, Parque Equitativa, Alto da Serra, Santo Antônio da Serra. 4ํㅡㅁ DISTRITO: Xerém, Parque Capivari, Mantiqueira, Jardim Olimpo, Lamarão, Amapá[...] A saúde financeira de Duque de Caxias é alimentada principalmente pelas altas receitas do ICMS das empresas que vêm crescendo a cada ano. No entanto, as pesquisas que medem o Índice de Desenvolvimento Humano (IDH), índices direcionados às análises educacionais, de renda e de longevidade de uma população, indicam que o município é o $52^{\circ}$ do estado." (CAMARA MUNICIPAL DE DUQUE DE CAXIAS, 2015)

Dentre os diversos municípios da Baixada Fluminense, Duque de Caxias vem sofrendo grandes agravos ao longo dos anos, devido aos processos de formação da região metropolitana do Rio de Janeiro e a incorporação da Baixada Fluminense como região periférica da cidade carioca. Tudo isso está relacionado com a sua condição de proximidade com a zona norte e o centro da cidade do Rio de Janeiro e ao histórico de ocupação populacional e implantação das indústrias no município. Muitos desses agravos estão relacionados com a poluição industrial, ausência de infraestrutura urbana, questões habitacionais e degradação do meio ambiente. 
O município de Duque de Caxias, assim como grande parte da Baixada Fluminense, apresenta uma grande quantidade de contrastes sociais onde se perpetua a realidade ao longo dos anos de espaços desiguais, injustiças socioambientais e omissões políticas. Por isso, a realidade de Duque de Caxias demonstra que a situação de vulnerabilidade da população apresenta um grande interesse político, assim como afirma ROLNIK e CYMBALISTA:

"Desta forma, perpetua-se uma dinâmica altamente perversa do ponto de vista urbanístico e bastante rentável do ponto de vista político, na medida em que a própria condição de inseguridade redunda em vulnerabilidade e barganhas eleitorais." (ROLNIK e CYMBALISTA, 1997, p.8)

Como consequência dessa realidade urbana perversa, o resultado da crescente ocupação humana transforma o ambiente e consequentemente gera vários impactos ambientais, intensificando processos como de inundações, enchentes e movimentos de massa causadores de grandes prejuízos. A Baixada Fluminense é alvo recorrente de tais "catástrofes", como a que ocorreu no distrito de Xerém, Duque de Caxias, em Janeiro de 2013.

"[...] As enchentes e inundações na Baixada Fluminense datam desde os primórdios de ocupação deste território, mostrando que a priori esta é uma dinâmica inerente do ambiente de baixada em que se apresenta". Contudo, as formas de uso e ocupação da terra, capitaneada pela eliminação da vegetação e retilinização dos rios em busca da otimização de espaços para habitação tornaram este um problema cada vez mais de cunho social [...] Rapidamente lembrando o evento de Janeiro de 2013 em Xerém, bairro de Duque de Caxias, uma chuva de $212 \mathrm{~mm}$ em 24 horas afetou cerca de 200 pessoas com 3 vítimas fatais segundo a defesa civil municipal." (OSCAR JÚNIOR, 2013, p.205)

Desse modo, a produção do espaço de muitas localidades de Xerém se caracteriza por não apresentarem nenhuma infraestrutura básica e pelo fato de que muitas residências estão construídas em terrenos ambientalmente frágeis. Por isso intensifica-se o processo de vulnerabilização dos grupos sociais marcados pela exposição aos riscos, em virtude de sua condição habitacional.

Ao mesmo tempo, o processo de expansão do distrito de Xerém, vem acentuando desigualdades referentes à qualidade habitacional dos diferentes grupos sociais presentes em Xerém, uma vez que muitos condomínios 
residenciais vêm crescendo na região da Mantiquira (parcela do território de Xerém com melhor acesso a infraestrutura urbana). A expansão dos condomínios residenciais atende aos interesses dos agentes dominantes do espaço, que influenciam o mercado imobiliário, a construção civil e determina/fortalece o controle do poder político local.

Portanto, o fato de uma grande parcela da população do distrito de Xerém viver em áreas de riscos, em condições de vulnerabilidade, enquanto outra parte da população habita condomínios fechados em localidades infraestruturadas confirma o que SMITH se refere à produção de espaços desiguais ao dizer que: "[...] o capital não somente produz o espaço em geral, mas também produz as reais escalas espaciais que dão ao desenvolvimento desigual a sua coerência" (SMITH, 1988, p19).

Além de ser um território propício ao oportunismo político e econômico, Xerém, assim como muitos outros lugares da Baixada Fluminense é fonte de inúmeros perigos possíveis (riscos). Ao analisar a realidade da metrópole do Rio de Janeiro, percebe-se que os espaços segregados/periféricos das cidades passam por um processo constante de deterioração da qualidade de vida associada à degradação do meio ambiente e das condições habitacionais da população. A perversidade da realidade urbana das cidades fluminenses demonstra uma expansão dos modelos urbanísticos e habitacionais da especulação imobiliária, amparado pelos interesses e omissões das políticas públicas.

"Este modelo é promovido pela especulação imobiliária e sustentado pela irresponsabilidade e conivência da administração pública em sua atuação nas áreas de licenciamento e de fiscalização. A coletividade vem sendo vítima dos interesses das empresas do ramo imobiliário, com a cumplicidade do poder público. A ganância dessas grandes organizações, que não respeitam as normas edilícias e ambientais da cidade, gerou o caos em que hoje vivemos. Esse caos urbano tem como consequência a perda da qualidade de vida e do contato com a natureza." (FUKS, 1997, p.154)

O poder político aliado ao empreendedor imobiliário são agentes dominantes da produção do espaço. Tais causas dessa ligação geram consequências como o caos urbano e a degradação da qualidade de vida ambiental de grande parte da população (injustiça ambiental), intensificando a condição de vulnerabilidade dos 
grupos sociais de menor renda que ocupam os espaços mais frágeis do território. Por isso, o modelo de desenvolvimento que caracteriza as cidades brasileiras fortalece as injustiças ambientais, pois uma grande parcela dos grupos sociais marginalizados está exposta aos riscos sociais, ambientais, políticos e sanitários resultantes de uma lógica perversa de um sistema de produção e de apropriação do solo.

\section{CONSIDERAÇÕES FINAIS}

Ao ressaltar a complexidade da temática do risco, da vulnerabilidade e da (in)justiça ambiental, compreende-se que a geografia tem como fundamento $o$ interesse pelas relações sociais, ambientais e por suas traduções espaciais. Analisa-se que o risco e sua percepção não podem ser evidenciados sem que se considerem os processos e atores que os produziu e, principalmente, as relações com o espaço geográfico, os modos de ocupação do território, de suas diversas relações, conflitos e fluxos existentes. Por esses motivos, a geografia procura avançar e aprofundar o enriquecimento do debate e lutas por justiça ambiental.

A interpretação geográfica proposta nesse artigo sobre a produção dos espaços de riscos em Xerém se relaciona com a interação homem/natureza, ou seja, uma perspectiva que busca a totalidade. As dinâmicas naturais, as quais fogem da intervenção humana, interagem com as dinâmicas sociais, portanto as inundações e enchentes ocorridas em Xerém (2013) têm raízes no processo de urbanização ao longo da rede de drenagem do Rio João Pinto. Dessa forma, os riscos naturais são politicamente e socialmente construídos a partir do momento em que as políticas públicas não atendem aos grupos sociais de menor renda moradores de áreas de risco.

\section{REFERÊNCIAS BIBLIOGRÁFICAS}

ABREU, M (1997). A Evolução Urbana do Rio de Janeiro. Rio de Janeiro: Iplanario.p.156 
ACSELRAD, H, MELLO e C, BEZERRA, G (2009). O que é justiça ambiental. Rio de Janeiro: Garamond.p.149

CAMARA MUNICIPAL DE DUQUE DE CAXIAS (2015) http://www.cmdc.ri.gov.br/ visualizado em 2015

CASTRO, A (sem data). Glossário de Defesa Civil Estudos de Riscos e Medicina de Desastres. 5.ed. Ministério da Integração Nacional Secretaria Nacional de Defesa Civil.p.191

CORRÊA, L (1995). O Espaço Urbano. São Paulo: Editora Ática S.A. p.94

FARIAS, L.O. (2005). Diagnóstico das Condições Sócio-Econômicas e da Gestão Pública dos Municípios da Baixada Fluminense. Rio de Janeiro/Brasília: Ministério do Desenvolvimento Social e Combate à Fome Secretaria de Avaliação e Gestão da Informação Departamento de Avaliação e Monitoramento. 59p.

FUKS, M (2001). Conflitos Ambientais no Rio de Janeiro: Ação e Debate nas Arenas Públicas. Rio de Janeiro: UFRJ .p244.

LEFEBVRE, H (2001). O Direito à Cidade. 5. ed. Tradução de Rubens Eduardo Frias. São Paulo: Centauro Editora.

NUNES, L.H. (2015). Urbanização e Desastres Naturais: abrangência América do Sul. São Paulo: Oficina de Textos. 112p.

OSCAR JUNIOR, A (2012). A paisagem da Baixada Fluminense: Uma análise na perspectiva geológica. Revista Brasileira de Geografia Física V. 06, N. 02 (2013) 195-210

PORTO-GONÇALVES (2006). De saberes e territórios: diversidade e emancipação a partir da experiência latino-americana.

RICHEMOND e VEYRET (2013). Os Tipos de Riscos. In: VEYRET, Y. : o homem como vítima e agressor do meio ambiente. 2.ed. São Paulo: Contexto.p.63-76 ROLNIK, R (2002). É possível política urbana contra a exclusão? . Serviço Social e Sociedade, São Paulo - Editora Cortez, v. 72,p. 53-61

ROLNIK, R. (2008). A lógica da desordem. Le Monde Diplomatique Brasil ROLNIK, R. (2013). Política Urbana no Brasil - Esperança em Meio ao Caos? Revista da ANTP, São Paulo (2003) 
ROLNIK, R e CYMBALISTA, R (1997). Instrumentos Urbanísticos Contra Exclusão. São Paulo: Pólis.p.116

SANTOS, Milton (2002). A natureza do espaço: técnica e tempo, razão e emoção. São Paulo: Edusp

SMITH, N (1988). Desenvolvimento Desigual. Rio de Janeiro: Bertrand Brasil.p.243

THOURET, J (2013). Avaliação, prevenção e gestão dos riscos naturais nas cidades da América Latina. 2.ed. São Paulo: Contexto.p.83-101

VEYRET, Y (2013). Os riscos: o homem como vítima e agressor do meio ambiente. 2.ed. São Paulo: Contexto.p.320 